\title{
MOOD AND PERFORMANCE IN AIKIDO ATHLETES
}

\author{
W. Pieter ${ }^{1}$, M. S. Pieter ${ }^{2}$ \\ ${ }^{1}$ Department of Physical Education, \\ University of Asia and the Pacific, Pasig City, Philippines \\ ${ }^{2}$ Department of Neurosciences, School of Medical Sciences, \\ Science University of Malaysia, Kelantan, Malaysia
}

\section{ABSTRACT}

The purpose of this study was to assess the mood profile of successful and less successful aikidoka (aikido athletes). Subjects (45 men, 30.51 \pm 8.06 years, and 17 women, $27.29 \pm 6.94$ years) were administered the Brunel Mood Scale at a regional open aikido tournament in the south of England about one hour prior to competition. A 2-way (Gender $x$ Performance) ANOVA was employed to determine the differences in mood between male and female winning and losing aikidoka. The women scored higher on tension $(5.58 \pm 2.74$ vs. $4.04 \pm$ 3.02) $\left(\mathrm{p}=0.049\right.$, eta $\left.^{2}=0.065\right)$. The data were collapsed over performance and mood was compared between gender. The men $(0.76 \pm$ 1.81 vs. $0.06 \pm 0.24)$ were more depressed $(\mathrm{p}=0.015 ; \mathrm{d}=0.68)$ and fatigued $(3.16 \pm 4.17$ vs. $1.53 \pm 1.18, \mathrm{p}=0.021 ; \mathrm{d}=0.61)$. The depressed mood males scored higher on anger $(2.27 \pm 4.84$ vs. $0.24 \pm$ $0.82, \mathrm{p}=0.021, \mathrm{~d}=0.72)$ and were more fatigued $(5.45 \pm 4.37$ vs. $2.41 \pm 3.89, \mathrm{p}=0.034, \mathrm{~d}=0.74)$. It is concluded that the model by Lane and Terry [5] was supported by the current investigation.

Key words: mood, performance, aikido 


\section{INTRODUCTION}

It has been suggested that a positive mental health state is related to success in sport, i.e., "success in sport is inversely related with psychopathology" [11]. Mental health state refers to the athletes' response to training rather than their baseline psychological profile. Compared to less successful athletes and the general population, successful athletes show lower levels of anxiety, neuroticism, tension, depression, fatigue and other negative moods but they score higher on vigor, leading to the so-called iceberg profile [11,12].

Morgan's mental health model relates success in any given sport to a positive psychological profile as measured by mood states. A greater incidence of a decrease in performance is implicated in a less desirable mood profile. Several studies have shown this relationship to hold at both the elite and non-elite levels [e.g., 3, 4, 13, 14]. However, more recent research has shown that the iceberg profile may only distinguish between athletes and non-athletes, rather than between different skill levels [17].

McGowan and Miller [7] compared karate semifinalists in fighting and forms with those placed lower using the Profile of Mood States (POMS) [10] and found no difference in any of the mood subscales. When year-long competitions were taken into account, however, the successful competitors scored higher on anger. The authors hypothesized that the successful athletes use angry imagery to "psych" themselves up for competition. The same pattern was found in experienced karate athletes with first degree black belts scoring higher on anger than their higher ranked colleagues [9]. The investigators hypothesized that higher ranked black belts may be more selfconfident, so they may not need to use anger as a coping mechanism.

In a related study, McGowan and associates [8] compared karate athletes from different skill levels as indicated by belt rank and found that black belts were more fatigued than white belts at a state championship. At regional tournaments, a similar picture emerged with the black belts scoring higher on fatigue than brown, colored and white belts. The authors concluded that the iceberg profile may not be exhibited by even successful athletes one day prior to competition.

Terry and Slade [21] also reported that karateka (karate athletes) who won showed more anger as well as vigor, but they scored lower on the other moods. The iceberg profile was demonstrated for the successful karateka, although anger was above that predicted by the 
mental health model [11]. The authors reported that mood profile was an exceptionally good predictor of karate performance with losers scoring high on several subscales.

Lane and Terry [5] developed a conceptual model in which it was suggested that 1) relationships among independent moods will be stronger in those high in depression; 2) high depression will be associated with high scores in anger, confusion, fatigue and tension with low vigor; 3) regardless of the level of depression, vigor will be positively and linearly related to performance, while fatigue and confusion will be negatively related to performance; 4) in those with high depression, tension and anger will be inversely related to performance, but will show a curvilinear relationship in those low in depression.

Lane et al. [6] showed that tension and anger in kickboxers were associated with losing when accompanied by depression. Depression was associated with high scores on tension, anger, fatigue and confusion. Wong et al. [22] reported that only successful female adolescent karateka scored higher on anger, while several negative moods were higher in both male and female depressed mood groups.

No mood studies to date have been conducted on aikidoka (aikido athletes). The purpose of this investigation, therefore, was to appraise the mood profile of successful and less successful aikidoka. To this end, the relationship between mood profile and performance was assessed. In addition, the association between tension, anger, vigor, fatigue and confusion in aikidoka with depressed and non-depressed mood was estimated.

\section{METHODS}

The Brunel Mood Scale (BRUMS) [20] was administered to all black belt participants (45 men, $30.51 \pm 8.06$ years, and 17 women, $27.29 \pm$ 6.94 years) at a regional open aikido tournament in the south of England about one hour prior to competition. The response set used was 'How are you feeling right now?'

A 2-way (Gender x Performance) ANOVA was employed to determine the differences in mood between male and female winning and losing aikidoka. The level of significance was set at 0.05 . It was decided not to adjust the type 1 error for multiple comparisons, because the interest was in the comparisonwise error rate as the data 
were generated through actual observations. As well, the objective was to unearth any possible leads regarding the relationship between the independent and dependent variables $[1,18]$.

\section{RESULTS}

Table 1 shows descriptive statistics for mood states in aikidoka by gender and performance. There was no 2-way interaction for any of the mood subscales and neither was there a main effect for Performance $(\mathrm{p}>0.05$ each). The women, however, scored higher on tension $(5.58 \pm 2.74$ vs. $4.04 \pm 3.02)(p=0.049)$ but the effect was trivial $\left(\mathrm{eta}^{2}=0.065\right)$.

Table 1 Means and standard deviations in mood states in black belt aikidoka by gender and performance

\begin{tabular}{|l|c|c|c|c|}
\hline & \multicolumn{2}{|c|}{ Men } & \multicolumn{2}{c|}{ Women } \\
\hline & Winners & Losers & Winners & Losers \\
\hline $\mathrm{n}$ & 16 & 29 & 6 & 11 \\
\hline Tension & $4.19 \pm 3.23$ & $3.97 \pm 2.95$ & $5.83 \pm 3.13$ & $5.91 \pm 2.66$ \\
\hline Depression & $0.44 \pm 0.96$ & $0.93 \pm 2.14$ & $0.00 \pm 0.00$ & $0.00 \pm 0.00$ \\
\hline Anger & $0.06 \pm 0.25$ & $1.10 \pm 3.16$ & $0.17 \pm 0.41$ & $0.36 \pm 0.67$ \\
\hline Vigor & $6.56 \pm 3.31$ & $8.07 \pm 3.31$ & $6.67 \pm 1.21$ & $7.00 \pm 2.53$ \\
\hline Fatigue & $2.38 \pm 3.05$ & $3.59 \pm 4.67$ & $2.17 \pm 0.75$ & $1.82 \pm 1.25$ \\
\hline Confusion & $1.25 \pm 1.73$ & $1.97 \pm 3.18$ & $1.50 \pm 1.05$ & $1.55 \pm 1.51$ \\
\hline
\end{tabular}

Since no differences were found between successful and less successful competitors by sex, the data were collapsed over performance and mood states were compared between gender using an independent t-test.

Table 2 displays the means and standard deviations for mood states by gender. The women scored higher on tension $(p=0.032, d=0.64)$, while the men were more depressed $(p=0.015, d=0.68)$ and fatigued $(\mathrm{p}=0.021, \mathrm{~d}=0.61)$. 
Table 2 Descriptive statistics for mood states in black belt aikidoka by gender

\begin{tabular}{|l|c|c|}
\hline & Men & Women \\
\hline Tension & $4.04 \pm 3.02$ & $5.88 \pm 2.74$ \\
\hline Depression & $0.76 \pm 1.81$ & $0.06 \pm 0.24$ \\
\hline Anger & $0.73 \pm 2.57$ & $0.29 \pm 0.59$ \\
\hline Vigor & $7.53 \pm 3.35$ & $6.88 \pm 2.12$ \\
\hline Fatigue & $3.16 \pm 4.17$ & $1.53 \pm 1.18$ \\
\hline Confusion & $1.71 \pm 2.75$ & $1.53 \pm 1.33$ \\
\hline
\end{tabular}

Following the suggestion by Lane et al. [6] and Lane and Terry [5], the subjects were divided into those who showed depressed mood and those who did not. Since only one female aikidoka qualified for the "depressed mood" category, the analysis was restricted to the males (see Table 3). An independent t-test was used for the analysis, while Pearson correlations between subscales were also calculated.

Table 3 Descriptive statistics for mood states in male black belt aikidoka as a function of depressed mood

\begin{tabular}{|l|c|c|}
\hline & Non-depressed $(\mathrm{n}=34)$ & Depressed $(\mathrm{n}=11)$ \\
\hline Tension & $3.76 \pm 3.02$ & $4.91 \pm 2.99$ \\
\hline Depression & $0.00 \pm 0.00$ & $3.09 \pm 2.55$ \\
\hline Anger & $0.24 \pm 0.82$ & $2.27 \pm 4.84$ \\
\hline Vigor & $7.91 \pm 3.40$ & $6.36 \pm 3.04$ \\
\hline Fatigue & $2.41 \pm 3.89$ & $5.45 \pm 4.37$ \\
\hline Confusion & $1.47 \pm 2.35$ & $2.45 \pm 3.78$ \\
\hline
\end{tabular}

The depressed mood aikidoka scored higher on anger $(\mathrm{p}=0.021, \mathrm{~d}=$ $0.72)$ and they were also more fatigued $(p=0.034, d=0.74)$. Table 4 displays the correlation matrix between mood subscales in the nondepressed mood males. There were associations between tension and confusion $(p=0.001)$, between anger and fatigue $(p=0.043)$, anger and confusion $(\mathrm{p}=0.004)$ as well as between fatigue and confusion ( $\mathrm{p}$ $<0.001)$. 
Table 4 Correlations between pre-competition mood subscales in nondepressed male aikidoka

\begin{tabular}{|l|c|c|c|c|c|c|}
\hline & Tension & Depression & Anger & Vigor & Fatigue & Confusion \\
\hline Tension & - & & & & & \\
\hline Depression & & - & & & & \\
\hline Anger & 0.02 & - & - & & & \\
\hline Vigor & -0.14 & - & 0.07 & - & & \\
\hline Fatigue & 0.07 & - & $0.35^{*}$ & -0.05 & - & \\
\hline Confusion & $0.55^{*}$ & - & $0.48^{*}$ & -0.09 & $0.66^{*}$ & - \\
\hline
\end{tabular}

Table 5 depicts the correlation matrix between mood subscales in the depressed mood males. There were associations between depression and anger $(\mathrm{p}<0.001)$, depression and confusion $(\mathrm{p}<0.001)$, as well as between anger and confusion $(\mathrm{p}<0.001)$.

Table 5 Correlations between pre-competition mood subscales in depressed aikidoka

\begin{tabular}{|l|c|c|c|c|c|c|}
\hline & Tension & Depression & Anger & Vigor & Fatigue & Confusion \\
\hline Tension & - & & & & & \\
\hline Depression & 0.21 & - & & & & \\
\hline Anger & 0.21 & $0.96^{*}$ & - & & & \\
\hline Vigor & 0.35 & 0.03 & 0.12 & - & & \\
\hline Fatigue & -0.01 & 0.27 & 0.26 & -0.16 & - & \\
\hline Confusion & 0.20 & $0.88^{*}$ & $0.91^{*}$ & 0.29 & 0.40 & - \\
\hline
\end{tabular}

\section{DISCUSSION}

McGowan and Miller [7] initially also did not find any difference in psychological mood between successful and less successful karateka. However, when a longer competition period was taken into account, the winners were shown to score higher on anger, which was confirmed by later research $[9,19,21)$. Anger was also found to be higher in young successful taekwondo athletes, as well as tension [15], while Wong et al. [22] reported higher anger in female successful karateka.

One explanation may be that aikidoka spend time cultivating the self, which is not necessarily part of the curriculum for their 
counterparts in karate and taekwondo. In other words, the meditative aspects of aikido may have played a role in the athletes not using anger to psych themselves up. Another explanation may be that experience, both general aikido experience and aikido-specific competition experience, may have masked the relationship between mood and performance as was suggested for taekwondo [15]. Future research on aikidoka should include experience in the model to elucidate the effects, if any, of mood on performance.

Tension, depression and fatigue differentiated the women from the men with the former scoring higher on tension but lower on depression and fatigue. It is not clear why the women were more tense. It could be that they viewed their opponents as more difficult to beat, as was found in female softball players [2], which subsequently led to higher tension. Including experience in the model, as alluded to above, may shed light on the association between gender, tension and performance.

When depression was used to categorize the male aikidoka, the depressed mood athletes scored higher on anger and fatigue, as predicted by the conceptual model advanced by Lane and Terry [5]. The effect sizes were also large.

The correlations between subscales seem to confirm Lane's and Terry's [5] conceptual model. A significant positive association between fatigue and confusion is suggested to have a debilitative effect on performance in non-depressed mood individuals. On the other hand, the positive correlations between anger and depression as well as anger and confusion in depressed mood athletes are predicted to have debilitative effects on performance. In other words, although the aikido athletes may not have used anger to psych themselves up, it may still have played a role by virtue of its relationship with other negative moods.

Figure 1 displays the mood profile of aikidoka by gender compared to norms of adult athletes [20]. Neither the men nor the women showed the iceberg profile predicted by Morgan [11] as was also found in young taekwondo athletes using norms for athletes [15]. Other investigators, using McNair et al.'s [10] norms, also failed to find the iceberg profile [e.g., 2, 16]. Morgan [1] developed his model based on McNair et al.'s [10] norms. Future research may want to elucidate the relation between mood, performance and the mental health model by using norms for athletes. 


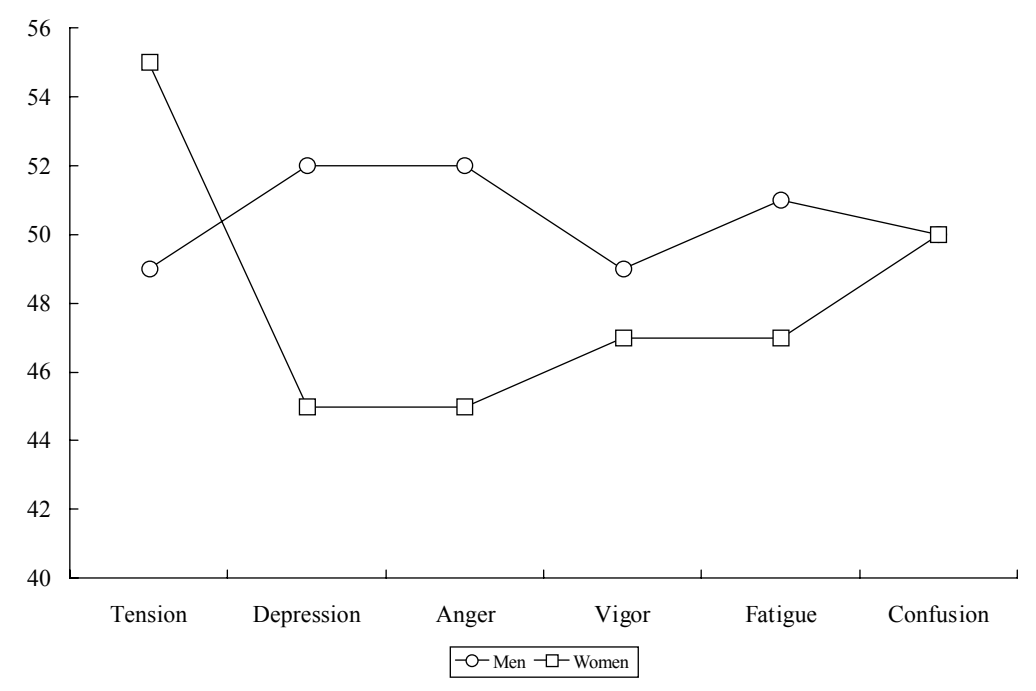

Figure 1. Mood profiles of black belt male and female aikidoka

\section{ACKNOWLEDGMENT}

The authors are grateful to Shaz John for assistance in data collection.

\section{REFERENCES}

1. Bender R., Lange S. (2001) Adjusting for multiple testing - when and how? J. Clin. Epidem. 54: 343-349.

2. Coker C., Mickle A. (2000) Stability of the iceberg profile as a function of perceived difficulty in defeating an opponent. Percept. Mot. Skills. 90 (3, Part 2): 1135-1138.

3. Frazier S. E. (1989) A comparison of team mood state profiles utilizing the mental health model. J. Hum. Mov. Stud. 16: 91-99.

4. Frazier S. E. (1988) Mood state profiles of chronic exercisers with different abilities. Int. J. Sport Psych. 19: 65-71. 
5. Lane A. M., Terry P.C. (2000) The nature of mood: development of a conceptual model with a focus on depression. J. Appl. Sport Psych. 12: $16-33$.

6. Lane A. M., Terry P. C., Karageorghis C. I., Lawson J. (1999) Mood states as predictors of kickboxing performance: a test of a conceptual model. J. Sports Sci. 17: 57-58.

7. McGowan R. W., Miller M. J. (1989) Differences in mood states between successful and less successful karate participants. Percept. Mot. Skills. 68: 505-506.

8. McGowan R. W., Miller M. J., Henschen K. (1990) Differences in mood states between belt ranks in karate tournament competitors. Percept. Mot. Skills. 71: 147-150.

9. McGowan R. W., Pierce E. F., Jordan D. (1992) Differences in precompetitive mood states between black belt ranks. Percept. Mot. Skills. 75: 123-128.

10. McNair D. M., Lorr M., Dropleman L. F. (1971) Profile of Mood States Manual. Educational and Industrial Testing Service, San Diego.

11. Morgan W. P. (1985) Selected psychological factors limiting performance: a mental health model. In: Limits of Human Performance. The Academy Papers \#18, D. H. Clarke H. M. Eckert (eds.), Champaign, IL: Human Kinetics Publishers, 70-80.

12. Morgan W. P. (1980) Test of champions: the iceberg profile Psych Today. 13: 92-93, 97-99, 102, 108.

13. Morgan W. P., Brown D. R., Raglin J. S., O’Connor P. J., Ellickson K. A. (1987) Psychological monitoring of overtraining and staleness. Brit. J. Sports Med. 21: 107-114.

14. Morgan W. P., Costill D. L., Flynn M., Raglin J. S., O’Connor P. J. (1988) Mood disturbance following increased training in swimmers. Med. Sci. Sports Exerc. 20: 408-414.

15. Pieter W., Wong R. S. K., Ampongan C. (2006). Mood and experience as correlates of performance in young Filipino athletes. Acta Kines. Univ. Tart. 11: 64-72.

16. Prapavessis H., Berger B., Grove J. (1992) The relationship of training and pre-competition mood states to swimming performance: an exploratory investigation. Aust. J. Sci. Med. Sport 24: 12-17.

17. Renger R. (1993) A review of the Profile of Mood States (POMS) in the prediction of Athletic success. J. Appl. Sport Psych. 5: 78-84.

18. Rothman K. J. (1990) No adjustments are needed for multiple comparisons. Epidem. 1: 43-46. 
19. Ruiz M., Hanin Y. (2003) Anger states in top karate athletes: an idiosyncratic description, II International Congress of Psychology Applied to Sport, Madrid, Spain.

20. Terry P. C., Lane A. M. (2003) User Guide for the Brunel Mood Scale (BRUMS). University of Southern Queensland, Australia, Toowoomba and University of Wolverhampton, Wolverhampton, UK.

21. Terry P. C., Slade A. (1995) Discriminant effectiveness of psychological state measures in predicting performance outcome in karate competition. Percept. Mot. Skills, 1: 275-286

22. Wong R. S. K., Thung J. S., Pieter W. (2006) Mood and performance in young Malaysian karateka. J. Sport Sci. Med. 5, Combat Sports Special Issue: 54-59.

\section{Address for correspondence:}

Willy Pieter

Department of Physical Education

University of Asia and the Pacific

Ortigas Center, Pasig City 1605

Philippines 